\title{
A Global Health Research Checklist for clinicians
}

\author{
Rasha D. Sawaya ${ }^{5^{*}}$ (D), Kristen A. Breslin ${ }^{1,2}$, Eiman Abdulrahman ${ }^{1,2}$, Jennifer I. Chapman ${ }^{1,2}$, Dafina M. Good ${ }^{1,2}$, \\ Lili Moran ${ }^{1,2}$, Paul C. Mullan ${ }^{3}$ and Oluwakemi Badaki-Makun ${ }^{4}$
}

\begin{abstract}
Global health research has become a priority in most international medical projects. However, it is a difficult endeavor, especially for a busy clinician. Navigating the ethics, methods, and local partnerships is essential yet daunting.

To date, there are no guidelines published to help clinicians initiate and complete successful global health research projects. This Global Health Research Checklist was developed to be used by clinicians or other health professionals for developing, implementing, and completing a successful research project in an international and often lowresource setting. It consists of five sections: Objective, Methodology, Institutional Review Board and Ethics, Culture and partnerships, and Logistics. We used individual experiences and published literature to develop and emphasize the key concepts. The checklist was trialed in two workshops and adjusted based on participants' feedback.
\end{abstract}

\section{Background}

Discussions surrounding global health research priorities, methods, ethics, and governance have increased in recent decades following reports highlighting disparities in global research resource allocation, with an emphasis on local research capacity building, respect for local innovation, and global research priority setting [1-3].

In parallel, clinicians are increasingly interested in global health work as indicated by the increasing number of training programs with global health rotations or tracks and global health education publications [4-6]. In academic settings, clinicians aim to marry their global health clinical interests with academic research in order to increase their impact in their partner communities as well as their academic footprint, thereby developing an academic niche. However, performing research in a different country can be a daunting proposition for the busy clinician with limited time and funding, and maintaining such a research career may be difficult $[7,8]$.

\footnotetext{
* Correspondence: rs139@aub.edu.lb

The work in this manuscript, The Global Health Research Checklist for physicians, has been formally presented at a workshop at the Pediatric Academic Society, on May 4, 2013, in Washington, DC.

${ }^{5}$ Division of Emergency Medicine, The American University of Beirut Medical Center, PO box 11-0236, Riad El-Solh, Beirut 1107 2020, Lebanon

Full list of author information is available at the end of the article
}

To date, there are no guidelines published to specifically help clinicians initiate and complete successful global health research projects. We define a research project as successful if it reached publication and had a meaningful impact on the local community.

Therefore, we endeavored to develop a Global Health Research Checklist to be used by clinicians as a structure for developing, implementing, and completing a successful research project in an international and often lowresource setting.

The Global Pediatric Emergency Medicine Group (gPEM Group) at Children's National Health Systems, George Washington University is a group of pediatric emergency medicine physicians with clinical and research experience in global health in various settings. Eight of us used a team approach based on our individual experiences to delineate the sections of the checklist. We used published literature to emphasize the key concepts as described below in detail. The checklist was trialed in two workshops including the Pediatric Academic Society meeting, Washington DC, and was adjusted based on participants' feedback which included changes in structure, number of sections, examples, and content flow.

This checklist consists of five sections that can be tackled in any order (Table 1): 
Table 1 Global health research checklist for clinicians

\begin{tabular}{l}
\hline Global Health Research Checklist \\
\hline Objective \\
o Needs assessment \\
o Study specific aim \\
o Global health/local community impact \\
o Is this section feasible? \\
Methodology \\
o Chose your GH research method \\
o Is this section feasible? \\
Institutional Review Board and Ethics \\
o Assess the ethical standards of the study \\
o Obtain IRB approval from your \\
home institution and local study site \\
o Is this section feasible? \\
Culture and partnership(s) \\
o Understand how the local culture \\
and community influences \\
your study or vice versa \\
o Identify local partners \\
o Define the roles in the collaboration \\
o Is this section feasible? \\
Logistics \\
o Timeline \\
o Funding \\
o International travel preparedness \\
o Is this section feasible?
\end{tabular}

1. Objective

2. Methodology

3. Institutional Review Board and Ethics

4. Culture and partnerships

5. Logistics

\section{The five sections of the checklist}

Two successful research projects [9-11] illustrate key concepts of the checklist and will be referred to in the discussion below (Table 2).

\section{Objective}

As with any sound research project, the first step is defining the research question and objectives. Generally, the project will grow out of personal interests or, preferably in global health, the needs of the local partner. A review of the literature will help identify work already done in the specified field as well as people who have worked in the area of research and the country of interest. Many professional organizations have interest groups to connect with those working in similar areas in global health [12]. Ideally, in global health settings where the territory and the system may be unfamiliar, the

Table 2 Case illustrations

Case one: "Pediatric Preparedness

of Lebanese Emergency Departments" [9]

Study summary:

A nationwide survey of all Lebanese hospitals with Emergency Departments (ED) that care for children highlighted that care was provided by a variety of physicians, most without any specific pediatric pediatric critical care, or pediatric emergency care training.

Study checklist key points:

- Objective: The goal of the principal investigator, RS, was to understand the precarious state of pediatric emergency medicine (PEM) in Lebanon in order to further its development. Specifically, she aimed to describe the EDs of hospitals that cared for children.

- Methodology: A written survey of all Lebanese hospitals with EDs that care for children.

- Culture and partnership: A partnership with an emergency medicine national leader was initially established via relationships that RS already had in place. Discussions between RS and the local partner lead to the specific aim. The participants' roles in the project were delineated beforehand and authorship credits assigned. The key roles of the local partner included identifying a local research assistant, the wording of the survey in order to facilitate understanding by Lebanese physicians, and helping approach the different hospitals in Lebanon. Culturally, Lebanese respond better to personal contact; therefore, speaking the local languages and establishing and maintaining relationships were key in identifying a local partner as well as recruiting hospitals.

- Institutional Review Board and Ethics: RS obtained Institutional Review Board (IRB) approval from the US home institution and from the local partners' institution.

- Logistics: Time and funding were all from personal resources.

Study impact:

A key result of the study, that unspecialized physicians care for acutely ill and injured children, identified areas for potential intervention. In response to these results, RS partnered with local physicians to create a PEM track in the following Lebanese Emergency Medicine Conference and is now developing a PEM curriculum for the first four-year Emergency Medicine residency program in Lebanon.
Case two: "Improving triage in a Botswana
Emergency Department". $[10,11]$

Study summary:

A quality improvement project team adapted a regionally tested triage system, the South African Triage Scale (SATS) and renamed it the Princess Marina Hospital Accident \& Emergency Triage Scale (PATS). Overall, overtriage rates and under-triage rates showed significant improvements, as PATS was more predictive of inpatient admission, Intensive Care Unit admission, and death in the ED than the prior triage system.

Study checklist key points:

- Objective: The Princess Marina Hospital Accident \& Emergency (PMH

A\&E) leadership approached and partnered with the principal

investigator, PM, to improve their triage system.

- Methodology: Using the adapted SATS allowed, a SATS team of trainers, that was available in the region, to assist in the training of trainers within the PMH A\&E group.

- Culture and Partnerships: PM spent 2 years in Botswana working with physicians, developing partnerships and gaining familiarity with the local medical system and culture. A memorandum of understanding (MOU) was established between the senior hospital leadership in Botswana and PM's sponsoring US institution. The role of PM in the project was to travel a few times per year from his home institution to organize the local staff in Botswana to design the project, build up local capacity to continue to manage it, and ensure its sustainability.

- Institutional Review Board and Ethics: All of the data collected and analyzed received approval from the IRBs of PMH, the Botswana Ministry of Health, the University of Botswana, and PM's US home institution. - Logistics: PM was able to secure funding for his travel from his home institution, the SATS trainers used their own funds to travel as an investment in their region's healthcare, and the limited funding required for the rest of the project activities all came from resources within $\mathrm{PMH}$ which had a vested interest in improving its triage system and outcomes. Study impact:

Developing this adapted triage system (PATS) fostered collaboration between two African countries as well as a US partner, and it promoted higher quality care for children with emergencies at the PMH A\&E. This triage system is in year 5 as of 2014 . 
investigator should identify both published and unpublished studies and learn about successes and roadblocks previous investigators faced. Most importantly, the onsite partners must be involved and invited to give feedback on the value and acceptability of the project, and a formal needs assessment can be a valuable tool.

For example, in case one, RS initially aimed to study pre-hospital care but in response to the local partner's needs, changed to study the emergency department.

Next, the investigator, together with on-site collaborators, should formulate specific objectives from the potential broad research questions. This may be a testable hypothesis, such as a new triage system will have less over-triage than the previous system (case two), or a may be a specific aim describing the training of providers caring for children in local emergency departments (case one).

Finally, the investigator is encouraged to consider the potential impact of the study being planned. These include answers to the following questions: Why is this question worth investigating? What are the potential implications on health outcomes of individual and of the community? Is there a possible impact beyond the population studied? What are the implications for the health resource utilization for the hospital or ministry of health? Will the implementation of this study drain the system or contribute to it?

\section{Methodology}

While any study design may be applied to global health research, the methodology selected will depend on the available data sources, ethical considerations, and resource limitations. A structured planning tool, such as a logic model [13], will help ensure all necessary resources and desired outputs are considered and will provide a map of the project to share with collaborators. Table 3 lists examples of study designs with special considerations for a global health setting.

One priority is defining the study population. In a global setting, the local team's input is invaluable to help understand the population and setting the investigator will be working in and how it will impact the study population.

Finally, the outcome specifies exactly what the study will measure. For example, to evaluate a new triage system, the investigator may want to measure how well the assigned triage level compares to the eventual disposition of the patients (case two). One could also measure staff satisfaction, length of stay, or in-hospital mortality. Using mortality as a measure can potentially show the importance of an intervention, but it can be difficult to demonstrate an impact and may require a larger sample size.

\section{Institutional review boards and ethics}

Significant discussion regarding the ethics of research in developing versus developed countries has occurred in recent decades, leading to the elaboration of guidelines specific to research in international settings [14-16]. These highlight the need to consider local cultures, economic capabilities, population needs, the local team's right to innovation, and self-governance as well as long-

Table 3 Examples of study design: advantages and pitfalls in a global health setting

\begin{tabular}{|c|c|c|}
\hline Study design & Examples & Considerations \\
\hline Experimental designs & $\begin{array}{l}\text { Clinical trial } \\
\text { Educational intervention } \\
\text { Quality/process improvement }\end{array}$ & $\begin{array}{l}\text { - For clinical trials, there must be } \\
\text { reasonable uncertainty about } \\
\text { whether the intervention or } \\
\text { standard of care is better (equipoise) [36 } \\
\text { - Educational and quality improvement } \\
\text { projects may allow comparison } \\
\text { of the same group before and after } \\
\text { - Outcomes from educational } \\
\text { interventions can be knowledge, } \\
\text { attitudes, or behaviors }\end{array}$ \\
\hline Observational designs [37] & $\begin{array}{l}\text { Prospective cohort } \\
\text { Retrospective cohort } \\
\text { Case-control } \\
\text { Descriptive epidemiology }\end{array}$ & $\begin{array}{l}\text { - Review of existing records from a } \\
\text { retrospective cohort or case-control } \\
\text { requires reliable clinical or } \\
\text { administrative records } \\
\text { - Surveys and interview tools } \\
\text { should be either validated tools } \\
\text { from the published literature or } \\
\text { carefully designed and reviewed [38] } \\
\text { - Prospective data collection } \\
\text { may require more time and personnel }\end{array}$ \\
\hline Qualitative design [39] & Interviews & $\begin{array}{l}\text { - May generate new ideas } \\
\text { for further testing }\end{array}$ \\
\hline Pilot study & Small-size project to assess feasibility & $\begin{array}{l}\text { - Identifies potential problems } \\
\text { prior to larger-scale study [40] }\end{array}$ \\
\hline
\end{tabular}


term benefits and sustainability to the community studied $[17,18]$.

The principle of respect for persons emphasizes the individual's right to self-determination and requires protection of those with a lower capacity for self-determination (e.g., children) [19]. Informed consent is an integral part of this principle and one that often causes complications in research implementation. For instance, in some societies, it is traditional and acceptable for the husband or another male relative to make decisions for a woman [14]. In others, the consent of community elders or senior family members must be sought before individual consent is obtained, if it is to be obtained at all [15]. Finally, illiteracy and cultural perceptions of western medicine may prove to be significant barriers to obtaining informed consent [20]. Discussions with local partners early on will be invaluable in understanding cultural implications of the proposed study and adjusting study design accordingly.

The principle of beneficence centers on nonmaleficence and maximizing benefits while minimizing risk [19]. One controversy arising from the implementation of this principle for research in developing countries is the question of "standard of care," i.e., should research studies in developing countries be required to provide the best available therapies (often standard of care in developed countries) as controls or should the standard of care in the local setting (frequently no or minimal therapy) be used? Such dilemmas have occurred frequently in published literature [20-22].

The principle of justice is exemplified by fairness of distribution. It requires appropriate selection of subjects and requires that the population in which the research study is being performed directly reap the benefits of the study [19]. Case 2 illustrates this principle: in Botswana, the host hospital was left with a new triage system uniquely designed specifically for it $[10,11]$.

To protect research subjects and follow the basic ethical principles outlined above, there is a requirement that proposed research studies be reviewed by independent bodies based on ethical merit and scientific validity $[14,15]$. In principle, research should be held to high standards regardless of location. Generally, studies in developing countries involving cross-national collaborations require review by Institutional Review Boards (IRBs) (or Research Ethics Committees) in both the developed and developing countries [14]. Identifying IRBs in developing countries may be difficult. If not available at the host institution, IRBs may be available at nearby large educational institutions/universities. In addition, local or national Ministries of Health could provide such services. Finally, if after a good faith effort to locate an IRB, but one does not exist at all in the country of interest, guidelines exist to assist in establishing one specifically for the study in question (Table 4).
Table 4 Institutional review board resources

Office for Human Research Protection (OHRP) [41]

Institutional Review Board Guidebook [42]

Institutional Review Board Identification:

Office for Human Research Protections (OHRP) Database for

Registered IORGs \& IRBs, Approved FWAs, and Documents Received in Last 60 Days [43]

\section{Culture and partnership(s)}

Culture is pervasive in life, impacting every aspect of human behavior. The undertaking of a project in a different country where language, customs, religion, economic, and political climates all vary requires significant preparation [23]. A transparent relationship with a focus on humility and respect for the local partner's culture is essential [24]. Sometimes, even a well thought out project may be affected by an unanticipated cultural misunderstanding [25-29].

In case one, RS had a rich understanding of the local culture given that she had lived there for many years. In creating the hospital surveys, since Arabic and English are the two languages utilized by most physicians, the team decided not to translate the survey in French, another main language in Lebanon. It was during the analysis that the word "resident" was noted to mean "someone who works in the hospital" for the physicians not trained in the US (or similar) medical system. This underscores the fact that even when a researcher has extensive knowledge about a culture, he or she may be from a different social class, ethnicity, or religion and therefore have a different understanding on certain issues and may not be aware of all the cultural variations within one nation.

In another unpublished example by LM, a project investigating the understanding of child abuse in Ghana was unsuccessful in getting local IRB approval because it was deemed to be too sensitive a topic with too many cultural implications for the local community.

Partnerships with local institutions, hospitals, or academic facilities are a necessary foundation to successful global health research projects. In creating a global health project, ideally, the first priority is to identify a local partner or institution that will serve as the "Local Champion" for the proposed project. This is often done over time, building a partnership individually or with a group. This long-term partnership is key to success as evidenced in the aboveillustrated cases. Secondly, the project should be mutually beneficial to all parties involved and the identified partner should be equally committed and interested in the research project. In case two, the local team approached PM, highlighting their need and commitment. In academic settings, identifying partner priorities for research and offering authorship 


\title{
A\&E TRIAGE QUALITY IMPROVEMENT PROJECT AGREEMENT
}

\author{
Between \\ Section of Emergency Medicine, Department of Pediatrics, Baylor College of Medicine \\ \& \\ Princess Marina Hospital Accident and Emergency (A \& E) Department \\ $\&$ \\ University of Botswana School of Medicine
}

\section{MISSION}

The Mission of the Department of Pediatrics, Baylor College of Medicine (BCM) is to support excellence in patient care, education and research with a commitment to quality service and cost-effective care to enhance the well-being of children locally, nationally, and internationally. The Section of Pediatric Emergency Medicine at BCM (SPEM$\mathrm{B}(\mathrm{M})$ is dedicated to assisting in the improvement of the adult and child triage system in the Accident and Emergency department of Princess Marina Hospital (AE-PMH).

The Mission of the Accident \& Emergency Department at Princess Marina Hospital is to provide excellent. resource-appropriate emergency care for the people of Gaborone and Botswana through measures of continuous quality improvement.

The Mission of the University of Botswana School of Medicine is to serve Botswana by excelling in clinical care, The Mission specialists and generalists alike to provide high-quality emergency medical care.

Together, the parties enter into this Project Agreement (PA) to mutually promote excellence in triage management. Accordingly, the Section of Pediatric Emergency Medicine, Baylor College of Medicine, Princess Marina Hospital, and the University of Botswana School of Medicine operating under this PA, agree as follows:

\section{RESPONSIBILITIES}

Each party will appoint a person to serve as the official contact and coordinate the activities of each organization in carrying out this MOU. The initial appointees of each organization are: , Dr. Alemayehu, or his deputy as specified below (AE-PMH), Dr Andrew Kestler (EM-UBSOM) and Dr Paul Mullan (SPEM-BCM). The organizations agree to the following tasks for this PA:

SPEM-BCM:

- SPEM-BCM will place one emergency pediatrician, Dr. Paul Mullan, in Gaborone, for at least two separate occasions to work primarily on the triage improvement project.

- Dr. Mullan will be available by mobile to provide paediatric consultation on emergency cases during his time on site.

- Dr. Mullan will be available by email or mobile for the duration of the project for consultation on the triage improvement project or for paediatric consultation on emergency cases. When feasible, efforts to make an initial response within 2 days of receipt of communication will be appreciated.

- Dr. Mullan will provide at least 8 hours per week of direct mentorship of medical officers in the Accident \& Emergency department while on site.

- Dr. Mullan will be responsible for lecturing, and coordinating the lecturing of other lecturers, for the triage improvement project while on site.

- Dr. Mullan will also make available at least one additional lecture on a topic of emergency medicine for the benefit of medical officer, medical students, and/or nurses while on site.

- Dr. Mullan will facilitate the submission of the project to the Human Research Development Committee

- Dr. Mullan will facilitate the writing of a manuscript detailing the results of the project; for his fellowship requirements, he will need to be the first author on the paper for its submission to a peer-reviewed journal. Dr. Mullan shall participate as needed in other activities with the Accident and Emergency department while on site. Such needs shall be communicated to Dr. Mullan by Drs. Kestler and Alemayehu in order to ensure that additional activities do not conflict with the primary goal of the triage intervention project.

AE-PMH:

- AE-PMH will help facilitate the integration of Dr. Mullan into the triage improvement project.

- AE-PMH will assist in the organization of teaching activities including those related to the triage improvement project and other teaching opportunities as outlined above.

- AE-PMH will make any requests for additional responsibilities to Dr Mullan in person. by mobile, or by email, or via EM-UBSOM.

- AE-PMH will refer any issues or problems with Dr. Mullan first to Dr. Mullan himself and, if not resolved. will thereafter be able to contact his supervisor. Dr. Sue Torrey of Department of Pediatrics, Baylor College of Medicine to report such issues. AE-PMH will contact EM-UBSOM early in the course of facing any such issues, in order to expedite resolution.

EM-UBSOM

- EM-UBSOM will function as the on-site project coordinator during the times that Dr. Mullan is not in-

- EM-UBSOM will ensure that all stakeholders are routinely updated on the status of the project.

- EM-UBSOM will be available by email or mobile for the duration of the project for consultation on the triage improvement project. When feasible, efforts to make an initial response within 2 days of receipt of communication will be appreciated.

\section{TERMS OF AGREEMENT}

The term of this Project Agreement (PA) is for a period of one year, from the effective date of this agreement, and may be extended upon written mutual agreement. It shall be reviewed at least once every three months to ensure written notice of 30 days.

Authorization

The signing of this PA is not a formal undertaking. It implies that the signatories will strive to reach, to the best of their ability, the objectives stated in the PA. On behalf of their respective institutions, the following signatories of this PA commit to its further development and implementation:

Fig. 1 Example of a memorandum of understanding 
roles can be a motivating factor. Finally, delineating clear roles and expectations of both partners involved through memorandums of agreement/understanding (MOA/MOU) (Fig. 1) will provide concrete guidance for the project partnership. This could include responsibilities such as funding, housing, teaching, and authorship. Ideally, if these three key concepts are present then a successful partnership and a global health project are feasible $[8,30-32]$. Table 5 presents priorities and pitfalls in creating durable and productive partnerships.

\section{Logistics}

The successful completion of an international project depends largely on logistical planning of timelines, budget, implementation, and manuscript publishing.

Timelines should include time for local partner identification, study design and development, data collection, and manuscript writing and submission. Careful planning should account for differing cultures and potential delays, such as availability of local partners and obtaining local IRB approval.

Expenses should be projected early in the project and funding options explored. Oftentimes, the pilot study may have to be funded by personal means. However, a partial list of potential funding agencies for clinicians is available in Table 6. Recently, Hansoti et al. described the potential funding opportunities available specifically for emergency medicine physicians working in international settings. This paper

Table 5 Priorities and pitfalls in creating durable and productive partnerships

\begin{tabular}{|c|c|}
\hline Priorities & Pitfalls \\
\hline Mutual benefit & $\begin{array}{l}\text { Not understanding } \\
\text { partner priorities or } \\
\text { imposing external priorities }\end{array}$ \\
\hline $\begin{array}{l}\text { Mutual investment/ } \\
\text { involvement }\end{array}$ & $\begin{array}{l}\text { Not engaging key } \\
\text { stakeholders as a voice } \\
\text { in the "decision } \\
\text { making" process }\end{array}$ \\
\hline $\begin{array}{l}\text { Identify funding and } \\
\text { mobilization of resources }\end{array}$ & $\begin{array}{l}\text { Wasting recipient hospital } \\
\text { or country resources }\end{array}$ \\
\hline Minimize inequity & Unilateral interest \\
\hline Find a local champion & $\begin{array}{l}\text { Not understanding or } \\
\text { identifying unique barriers to } \\
\text { specific champions and/or } \\
\text { research in partnering countries }\end{array}$ \\
\hline Promote local ownership & "One size fits all mentality" \\
\hline Partner capacity building & Sustainability of programs or projects \\
\hline Relationship building & $\begin{array}{l}\text { Lack of trust and transparency in } \\
\text { partnerships }\end{array}$ \\
\hline $\begin{array}{l}\text { Understanding the political } \\
\text { and legal landscape }\end{array}$ & $\begin{array}{l}\text { Not discussing these issues with local } \\
\text { partner and institution }\end{array}$ \\
\hline
\end{tabular}

helps the reader navigate the complicated world of grants from seed to federal grants [33]. In addition, gaining the support of the principal investigator's home institution can be critical in funding time and travel expenses, as well as finding home institution global research funds.

In planning for project implementation, health and safety travel preparedness should not be ignored. Research trip requirements can be found by visiting the public domains of the Centers for Disease Control and Prevention [34], the World Health Organization [35], the home country's embassy website in the partner country as well as the partnering country's embassy websites. Planning for the visiting members of the team with clear roles and check-in mechanisms is critical for both the safety and functionality of the team.

\section{Limitations}

First, this checklist is limited by the fact that it is focused on clinicians and may not benefit other researchers involved in global health research such as public health providers. However, this is a deliberate choice, as it is a gap in the published literature and based on our prior experience an invaluable tool for our clinician colleagues.

Moreover, this checklist requires validation, which we will be undertaking.

\section{Conclusion}

We have delineated a comprehensive Global Health Research Checklist for clinicians, consisting of five sections that we have deemed necessary for a successful project. We believe that the checklist presented above is a valuable tool to plan and assess the feasibility of global health research projects. We have highlighted specific areas a clinician researcher should

Table 6 Global Health Research Funding opportunities for clinicians

American Academic of Pediatrics, Section

on International Child Health (SOICH) [12]

Fogarty International Clinical Research

Scholars \& Fellow Program Support Center [44]

USAID Global Health Fellows II [45]

Fogarty International Center:

- NIH funding opportunities [46]

- Non-NIH funding opportunities for faculty [47]

Bill \& Melinda Gates Foundation. Grant opportunities [48]

Grand Challenges in Global Health. Grant opportunities [49] Pivot $^{\text {TM }}[50]$

National Science Foundation. Active funding opportunities [51]

Office of International Affairs. Global Health Initiative--funding [52]

Grand challenges in global health. Rewarding innovative ideas [53]

Center for global health. The University of Chicago. Funding agencies for global

health opportunities [54]

American Nurses Association. Opportunities for research funding [55] 


\section{Your Personal Project Checklist}

What would you like to study?

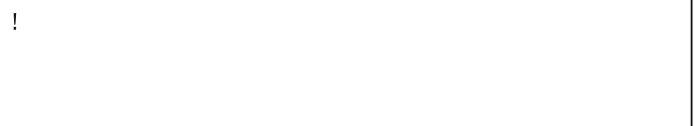

Objective:

-What's your global objective?

Why are you doing this study?

- What's your specific aim?

- How does your study impact the local community's health?

Is this section feasible? Y/N

Methodology:

- What method would best answer your question?

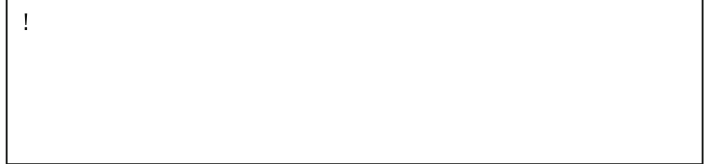

Is this section feasible? Y/N

Institutional Review Board \& Ethics:

- Does your study and methodology abide by the ethical standards of your own institution and country as well as that of the study site?

Do you know how to submit your protocol to your home IRB?

- Do you know what IRB to submit to at your study site?

Is this section feasible? $\mathrm{Y} / \mathrm{N}$

Culture \& Partnership(s):

- Is your study and method sensitive to the local culture?

- Will your study be affected by the local culture? If so, how? Can you take that into account?

Who are (could be) your local partners?

What are the roles in the collaboration?

Is this section feasible? $\mathrm{Y} / \mathrm{N}$

Logistics:

- What is your approximate timeline for each step?

How will you fund this study?

- Are you prepared to travel to and live at your site?

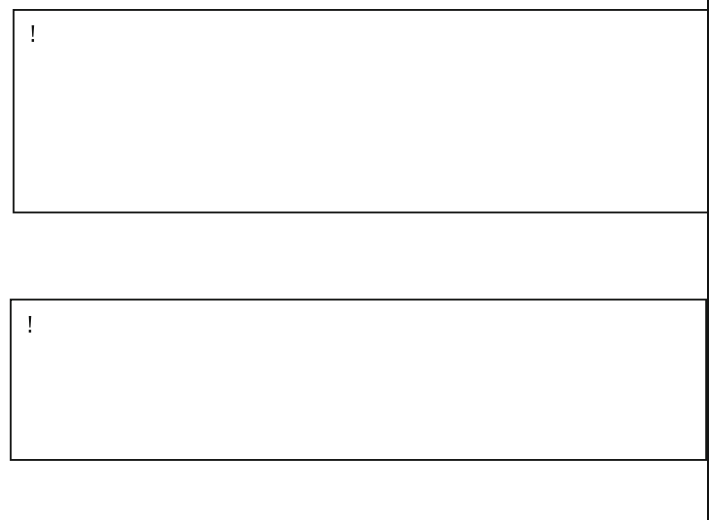

Is this section feasible? $\mathrm{Y} / \mathrm{N}$

Fig. 2 Personal checklist

address when embarking on a global health research project. Figure 2 reproduces the checklist with specific questions to be used by the clinician researcher. Having developed this checklist based on experience and currently available literature, our future aim is to validate it.

\section{Acknowledgements}

Not applicable.

\section{Funding}

Not applicable.

\section{Availability of data and materials}

Data sharing not applicable to this article as no datasets were generated or analyzed during the current study.

\section{Authors' contributions}

RS generated the idea and contributed to the study design, literature search, figures, writing, editing, group organization, and submission of the

manuscript. KB and OBK contributed to the study design, literature search, figures, writing, and editing of the manuscript. RS, LM, and PM contributed their case studies based on their research work. EA, JC, DG, LM, and PM all contributed equally to the study design, literature search, figures, and writing of the manuscript. All authors read and approved the final manuscript.

Ethics approval and consent to participate

Not applicable.

Consent for publication

Not applicable.

\section{Competing interests}

The authors declare that they have no competing interests. 


\section{Publisher's Note}

Springer Nature remains neutral with regard to jurisdictional claims in published maps and institutional affiliations.

\section{Author details}

${ }^{1}$ Children's National Health System, The George Washington University School of Medicine and Health Sciences, 111, Michigan Ave, NW Washington, DC 20010, USA. 'Division of Emergency Medicine, Children's National Medical Center, 111, Michigan Ave, NW, Washington, DC 20010, USA. ${ }^{3}$ Department of Emergency Medicine, Children's Hospital of The King's Daughters, 601 Children's Lane, Norfolk, VA 23507, USA. "Department of Pediatrics, Division of Emergency Medicine, Johns Hopkins University School of Medicine, 1800 Orleans St, Baltimore, MD 21287, USA. ${ }^{5}$ Division of Emergency Medicine, The American University of Beirut Medical Center, PO box 11-0236, Riad El-Solh, Beirut 1107 2020, Lebanon.

Received: 27 December 2017 Accepted: 23 February 2018 Published online: 19 April 2018

\section{References}

1. Global Forum for Health Research, World Health Organization. The 10/90 (ten/ninety) report on health research 2001-2002. In: The global forum for health research; 2000. http://announcementsfiles.cohred.org/gfhr_pub/ assoc/s14791e/s14791e.pdf. Accessed 9 Dec 2017.

2. Lee K, Mills A. Strengthening governance for global health research. BMJ. 2000:321:775-6.

3. De Lisle H, Roberts, JH, Munro M, Jones L, Gyorkos T. The role of NGOs in global health research for development. Health Res Pol Syst. 2005;3:3.

4. Dixon CA, Castillo J, Castillo H, Hom KA, Schubert C. Global health opportunities within pediatric subspecialty fellowship training programs: surveying the virtual landscape. BMC Med Educ. 2013;13:88.

5. Calland JF, Petroze RT, Abelson J, Kraus E. Engaging academic surgery in global health: challenges and opportunities in the development of an academic track in global surgery. Surgery. 2013;153(3):316-20.

6. Anspacher M, Frintner MP, Denno D, et al. Global health education for pediatric residents: a national survey. Pediatrics. 2011;128(4):e959-6.

7. Greyson SR, Richards AK, Coupet S, Desal MM, Padela Al. Global health experiences of US physicians: a mixed methods survey of clinicianresearchers and health policy leaders. Glob Health. 2013;9:19.

8. Ridde V, Capelle F. The global health research and the challenges of the North-South partnerships. Can J of Public Health. 2011;102(2):152-6.

9. Sawaya RD, Dayan P, Pusic MV, Nasri H, Kazzi AA. Pediatric preparedness of Lebanese emergency departments. J Emerg Med. 2013;44(6):1180-7.

10. Mullan PC, Torrey SB, Chandra A, Caruso N, Kestler A. Reduced overtriage and undertriage with a new triage system in an urban accident and emergency department in Botswana: a cohort study. Emerg Med J. 2014;31(5):356-60.

11. Twomey M, Mullan PC, Torrey SB, Wallis L, Kestler A. The Princess Marina Hospital accident and emergency triage scale provides highly reliable triage acuity ratings. Emerg Med J. 2012;29(8):650-3.

12. American Academic of Pediatrics, Section on International Child Health. Available at: https://www.aap.org/en-us/about-the-aap/CommitteesCouncils-Sections/soich/Pages/default.aspx. Accessed on 9 Dec 2017.

13. W.K. Kellogg Foundation. Logic Model Development Guide. Available at http://www.wkkf.org/knowledge-center/resources/2006/02/wk-kelloggfoundation-logic-model-development-guide.aspx. Accessed 1 Dec 2017.

14. Calman KC. The ethics of research related to healthcare in developing countries. Oxford: Nuffield Council on Bioethics; 2002. p. 1-189.

15. Calman KC. The ethics of research related to healthcare in developing countries: follow-up. Oxford: Nuffield Council on Bioethics; 2004. p. 1-128.

16. Council for International Organizations of Medical Sciences. International ethical guidelines for biomedical research involving human subjects. Bul Med Ethics. 2002;182:17-23.

17. Lamonte R, Spiegel J. Setting global health research priorities. BMJ V. 2003;326:723-4

18. Ijsselmuiden CB, Kass NE, Sewankambo KN, Lavery JV. Evolving values in ethics and global health research. Global Public Health. 2010;5(2):154-63.

19. The National Commission for the Protection of Human Subjects of Biomedical and Behavioral Research. The Belmont report--ethical principles and guidelines for the protection of human subjects of research. In: Office of Human Research Protection; 1979. http://www.hhs.gov/ohrp/ humansubjects/guidance/belmont.html. Accessed 9 Dec 2017.
20. Cash R, Wikler D, Saxena A, Capron A. Casebook on ethical issues in international health research. World Health Organization; 2009. http://apps. who.int/iris/bitstream/10665/44118/4/9789241547727_eng.pdf. Accessed 9 Dec 2017.

21. Charatan F. Surfactant trial in Latin American infants criticized. BMJ. 2001;322:575.

22. Centers for Disease Control and Prevention (CDC). Administration of zidovudine during late pregnancy and delivery to prevent perinatal HIV transmission-Thailand, 1996-1998. MMWR Morb Mortal Wkly Rep. 1998:47(8):151-4.

23. Partners in Health. PIH Program Management Guide. In: Knowledge center global health discourse and tools; 2011. www.pih.org/library/pih-programmanagement-guide. Accessed 9 Dec 2017.

24. Riddle V, Capelle F. Global health research challenges with a North-South partnership. Can J Public Health. 2011;102(2):152-6.

25. Turner L. From the local to the global: bioethics and the concept of culture. Med Philos. 2005:30:305-20.

26. Tseng, WS. (April 2004). Culture and psychotherapy: Asian perspectives. J Ment Health 2004; 13(2), 151-161.

27. Patel V, Chowdhary N, Rahman A, Verdeli H. Improving access to psychological treatments: lessons from developing countries. Behav Res Ther. 2011;49(9):523-8.

28. Ongugo K, Hall J, Attia J. Implementing tuberculosis control in Papua New Guinea: a clash of culture and science? J Community Health. 2011;36(3):423-30.

29. Storti C. Culture matters: the peace corps cross-cultural workbook. In: Peace corps information collection and exchange. Online edition; 2011.

30. Little M, Sisco C, Schappert J. The business of a better world. In: Working toward transformational health partnerships in low- and middle-income countries; 2012. https://www.bsr.org/reports/BSR_Working_Toward_ Transformational_Health_Partnerships.pdf. Accessed 9 Dec 2017.

31. Caines K, Buse K, Carlson C, et al. Assessing the impact of global health partnerships. In: Department For International Development (DFID) health resource center; 2007. http://www2.ohchr.org/english/issues/development/ docs/WHO synthesis.pdf. Accessed 9 Dec 2017.

32. Buse K, Hammer AM. Seven habits of highly effective global publicprivate health partnerships: practices and potential. Soc Sci Med. 2007; 64(2):259-71.

33. Hansoti B, Levine A, Ganti $L$, et al. Funding global emergency medicine research--from seed grants to NIH support. Int J Emerg Med. 2016;9:27.

34. Center for Disease Control and Prevention. www.cdc.gov. Accessed 9 Dec 2017.

35. World Health Organization. www.who.int/en/. Accessed 9 Dec 2017

36. Hey SP, London AJ, Weijer C, Miller F. Is the concept of clinical equipoise still relevant to research? BMJ. 2017;359:j5787.

37. Ressing M, Blettner M, Klug SJ. Data analysis of epidemiological studies: part 11 of a series on evaluation of scientific publications. Dtsch Arztebl Int. 2010;107(11):187-92

38. Kimberlin $\mathrm{CL}$, Winterstein AG. Validity and reliability of measurement instruments used in research. Am J Health Syst Pharm. 2008;65(23): 2276-84.

39. Giacomini MK, Cook DJ. Users' guides to the medical literature: XXIII. Qualitative research in health care a. Are the results of the study valid? Evidence-based medicine working group. JAMA. 2000;284(3) 357-62.

40. Mennin S, Kalishman S, Eklund MA, Friedman S, Morahan PS, Burdick W. Project-based faculty development by international health professions educators: practical strategies. Med Teach. 2013;35(2):e971-7.

41. United States Department of Health and Human Services. Office for Human Research Projection (OHRP). https://www.hhs.gov/ohrp/. Accessed 9 Dec 2017.

42. Penslar RL, Institutional Review Board guidebook. 1993. http://www.hhs.gov/ ohrp/archive/irb/irb_guidebook.htm. Accessed 9 Dec 2017.

43. United States Department of Health \& Human Services, The Office for Human Research Protection. Office for Human Research Protections (OHRP) Database for Registered IORGs \& IRBs, Approved FWAs, and Documents Received in Last 60 Days. http://ohrp.cit.nih.gov/search/search.aspx?styp= bsc. Accessed 9 Dec 2017.

44. The Global Health Program for fellows and scholars. Fogarty International Center. National Institute of Health. https://www.fic.nih.gov/Programs/ pages/scholars-fellows-global-health.aspx. Accessed Dec 2017.

45. USAID global health fellows II. http://www.ghfp.net/. Accessed 9 Dec 2017.

46. Funding opportunities. Fogarty International Center. http://www.fic.nih.gov/ Funding/Pages/default.aspx. Accessed 9 Dec 2017.

47. Non-NIH funding opportunities for faculty. Fogarty International Center https:// www.fic.nih.gov/Funding/NonNIH/Pages/default.aspx. Accessed 5 Mar 2018. 
48. Grant opportunities. Bill \& Melinda Gates Foundation. http://www gatesfoundation.org/How-We-Work/General-Information/GrantOpportunities. Accessed 9 Dec 2017.

49. Grant opportunities. Grand Challenges in Global Health. http://umw. grandchallenges.org/GrantOpportunities/Pages/default.aspx. Accessed 9 Dec 2017.

50. Pivot $^{\mathrm{TM}}$. http://pivot.cos.com/. Accessed 9 Dec 2017.

51. Active funding opportunities. National Science Foundation. http://www.nsf. gov/funding/pgm_list.jsp?org=NSF\&ord=rcnt. Accessed 9 Dec 2017.

52. Global health initiative--funding. Office of International Affairs. The Ohio State University. http://oia.ncsu.edu/globalhealth/funding. Accessed 6 Dec 2017.

53. Rewarding innovative ideas. Grand Challenges in Global Health. The Bill and Melinda Gates Foundation. http://www.grandchallenges.org/explorations/ Pages/introduction.aspx. Accessed 9 Dec 2017.

54. Funding agencies for global health opportunities. Center for Global Health The University of Chicago. https://cgh.uchicago.edu/page/funding-agenciesglobal-health-opportunities. Accessed 9 Dec 2017.

55. American Nurses Association. Opportunities for research funding. http:// www.nursingworld.org/MainMenuCategories/

ThePracticeofProfessionalNursing/Improving-Your-Practice/Research-Toolkit/ Research-Funding. Accessed 9 Dec 2017.

\section{Submit your manuscript to a SpringerOpen ${ }^{\odot}$ journal and benefit from:}

- Convenient online submission

- Rigorous peer review

- Open access: articles freely available online

- High visibility within the field

- Retaining the copyright to your article

Submit your next manuscript at $>$ springeropen.com 